\title{
Copolymerization of Poly(butylene succinate) with 3-Alkoxy-1,2-propanediols
}

\author{
Akihiro Oishi, Hironori NAKANO, ${ }^{*}$ Ken-ichi Fujita, Makoto YUASA, ${ }^{*}$ \\ and Yoichi TAGUCHI ${ }^{\dagger}$ \\ National Institute of Advanced Industrial Science and Technology (AIST), \\ Central 5, 1-1-1 Higashi, Tsukuba, Ibaraki 305-8565, Japan \\ ${ }^{*}$ Faculty of Science and Technology, Tokyo University of Science, \\ 2641 Yamazaki, Noda, Chiba 278-8510, Japan
}

(Received May 1, 2002; Accepted August 11, 2002)

\begin{abstract}
A copolymer of poly(butylene succinate) was produced from dimethyl succinate (1), 1,4-butanediol (2) and 3-alkoxy-1,2-propanediol (3) such as 3-methoxy-1, 2-propanediol (3a), 3-allyloxy-1, 2-propanediol (3b) and 3-octadecyloxy-1, 2-propanediol (3c). Copolymers of high molecular weight were obtained when a small amount of 3 was included, but molecular weight decreased with increasing amount of $\mathbf{3}$. Copolymers including a small amount of 3 had larger break strain than homopolymer. Although the copolymer including $0.3 \% \mathbf{3 c}$ possessing an alkyl long chain had the largest break strain, copolymers including more amount of $\mathbf{3 c}$ had lower molecular weights and lower break strain because of the low reactivity of secondary alcohol of $\mathbf{3 c}$. To accelerate copolymerization a new method was designed in which diols of $\mathbf{3 c}$ are first esterified by succinic anhydride and then copolymerization. When $0-5 \mathrm{~mol} \%$ of 3c was used in copolymerization by the method, copolymers with $M_{\mathrm{n}}$ higher than 60000 were obtained. The copolymer including $5 \mathrm{~mol} \%$ of $\mathbf{3 c}$ showed break stress reached of $833 \%$, and the biodegradation rate of the copolymer was slower than homopolymer.

KEY WORDS Poly(butylene succinate) / 3-Alkoxy-1, 2-propandiol / 3-Octadecyloxy-1,2-propanediol / Copolymer / Break Strain / Biodegradation /
\end{abstract}

Much attention has been paid to biodegradable polymers for environmentally friendly plastics. They finally decompose into carbon dioxide and water in nature. Aliphatic polyesters are good biodegradable polymers and have many excellent properties. ${ }^{1-4}$ Poly(butylene succinate) (PBS), an aliphatic polyester, has good thermal and mechanical properties similar to polyethylene and polypropylene. Improvement of PBS properties has been widely investigated by many scientists. ${ }^{5-7}$

Recently, we reported that PBS copolymerized with monoacylglycerol was produced from dimethyl succinate, 1,4-butanediol and monoacylglycerol such as monolaurin, monostearin, and monoolein. ${ }^{8}$ The break stress of the copolymer containing $0.3 \mathrm{~mol} \%$ monostearin or monoolein to dimethyl succinate was three times that of the PBS homopolymer, though the number average molecular weight and thermal properties of copolymer were the same as those of the homopolymer. But, at more than $1 \mathrm{~mol} \%$ monoacylglycerol to dimethyl succinate for copolymerization, gelation occurred and the copolymers were insoluble in chloroform owing to transesterification of a portion of the monoacylglycerol component.

New copolymers including 3-alkoxy-1,2-propanediol such as 3-methoxy, 3-allyloxy, and 3-octadecyloxy1,2-propnanediol were synthesized, and thermal, me-

${ }^{\dagger}$ To whom correspondence should be addressed. chanical, and biodegradable properties of copolymers were studied.

\section{EXPERIMENTAL}

\section{Materials}

Dimethyl succinate (1), 1,4-butanediol (2), titanium tetraisopropoxide (Wako Pure Chemical), 3-methoxy1,2-propanediol (3a), 3-allyloxy-1,2-propanediol (3b) and 3-octadecyloxy-1,2-propanediol (3c) (Tokyo Kasei Kogyo) were used without further purification. Commercial compost soil (Tokawa Heiwa Noen) was purchased for biodegradation test.

\section{Analysis}

The number-average molecular weight $\left(M_{\mathrm{n}}\right)$ and polydispersity $\left(M_{\mathrm{w}} / M_{\mathrm{n}}\right)$ of polymers were determined by gel permeation chromatography (GPC) at column oven temperature $40^{\circ} \mathrm{C}$ on a Tosoh GPC system SC8020 equipped with two TSKgel columns (GMHXLL) using RI detector. Molecular weight was calibrated according to polystyrene standard. Chloroform was used as eluent at a flow rate of $1.0 \mathrm{~mL} \mathrm{~min}{ }^{-1}$.

The compositions of copolymers were analyzed by ${ }^{1} \mathrm{H}$ NMR spectra measured on a Varian Gemini 300BB spectrometer $(300 \mathrm{MHz})$.

The thermal properties of polymers, glass transition 


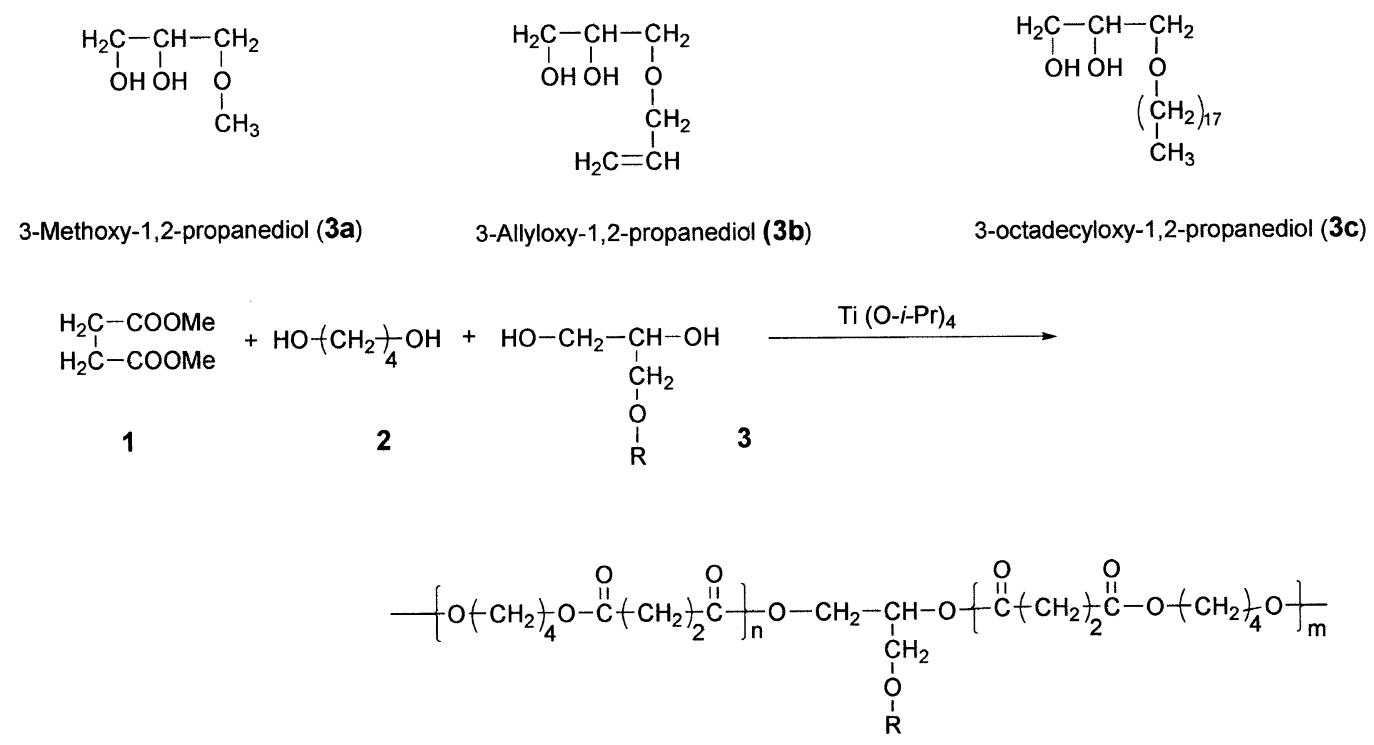

$\operatorname{PBSX}(X=M, A, 0)$

Scheme 1.

temperature $\left(T_{\mathrm{g}}\right)$, melting temperature $\left(T_{\mathrm{m}}\right)$, and heat of fusion $\left(\Delta H_{\mathrm{m}}\right)$ were examined by differential scanning calorimetry (DSC) on a Seiko DSC-220 apparatus, and $2 \%$ thermal decomposition temperature (Td2) was determined by thermogravimetry on Seiko TG/DTA-220 apparatus. Polymer samples were scanned from -100 to $200{ }^{\circ} \mathrm{C}$ at a heating rate of $20^{\circ} \mathrm{C} \mathrm{min}^{-1}$ under nitrogen stream. $T_{\mathrm{m}}, \Delta H_{\mathrm{m}}$, and $T_{\mathrm{g}}$ was determined in the second heating.

\section{Tensile Test}

Films (about $0.2 \mathrm{~mm}$ thick) were prepared by the heat-press method at $200 \mathrm{~kg} \mathrm{~cm}^{-2}$ and $140^{\circ} \mathrm{C}$. All tensile measurements were performed using a TOYO BALDWIN SS-207-EP tester at room temperature. Experiments were performed at a constant crosshead speed of $10 \mathrm{~mm} \mathrm{~min}^{-1}$. A least of three samples were tested under the same conditions for each polymer, and the average value was taken as representative.

\section{Degradation of Polymers}

Films of initial dimension $25 \times 25 \times 0.2 \mathrm{~mm}$ were placed in compost soil at $30^{\circ} \mathrm{C}$ and $95 \%$ moisture. The films were removed at regular intervals, washed with distilled water and dried to constant weight in vacuum before analysis. For each sample, three films were used and average weight-loss amount was taken as the result.

\section{Preparation of Copolymers}

A typical procedure was as follows. A three-necked $100 \mathrm{~mL}$ flask was charged with $180 \mathrm{mmol}$ dimethyl succinate, $187 \mathrm{mmol}$ 1,4-butanediol, $0.54 \mathrm{mmol} \mathrm{3-}$ octadecyloxy-1,2- propanediol and $0.10 \mathrm{mmol}$ titanium tetraisopropoxide under dry $\mathrm{N}_{2}$ atmosphere. The flask provided with a gas introduction inlet and outlet connected with a condenser was first immersed in a silicon oil bath preset at $215^{\circ} \mathrm{C}$, and heated to remove the esterification reaction byproduct of methanol for $1 \mathrm{~h}$. Subsequently, the condenser was removed, and polycondensation was carried out under gradually reduced pressure with a final degree of vacuum less than $0.1 \mathrm{mmHg}$. Polycondensation was ended when the viscosity of the product was high enough.

\section{RESULTS AND DISCUSSION}

Copolymers of PBS with monoacylglycerol show higher break strain than PBS homopolymer, but gelation based on the transesterification of monoacylglycerol takes place. ${ }^{8}$ Although 3-alkoxy-1,2-propanediols bear close resemblance to monoacylglycerol, they do not transesterificate owing to have ether bonds instead of ester bonds of monoglyceride. 3-Alkoxy-1,2propanediol instead of monoacylglycerol should thus improve the break strain of PBS copolymers without gelation. So the synthesis of PBS copolymers was carried out from dimethyl succinate (1), 1,4butanediol (2), and 3-alkoxy-1,2-propanediol (3) such as 3-methoxy-1,2-propanediol (3a), 3-allyloxy-1,2propanediol (3b), and 3-octadecyloxy-1,2- propanediol (3c).

Table I shows number-average molecular weights $\left(M_{\mathrm{n}}\right)$ and molecular weight distribution $\left(M_{\mathrm{w}} / M_{\mathrm{n}}\right)$ of copolymers including $\mathbf{3 a}, \mathbf{3 b}$, and $\mathbf{3 c}$. High molecular weight copolymers were obtained when a small amount of $\mathbf{3}$ was added. Molecular weights of copolymers decreased with increasing amount of 3 (Runs 5, 9, and 13 ), and only $1 \mathrm{~mol} \%$ of $\mathbf{3 c}$ having an alkyl long chain 
Table I. $M_{\mathrm{n}}$ and $M_{\mathrm{w}} / M_{\mathrm{n}}$ of copolymers including 3-alkoxy-1,2-propanediol ${ }^{\mathrm{a}}$

\begin{tabular}{|c|c|c|c|c|c|c|c|c|c|}
\hline Run & $\frac{1}{\mathrm{mmol}}$ & $\frac{\mathbf{2}}{\mathrm{mmol}}$ & 3 & $\mathbf{R}$ & mmol & $\frac{3 / 1^{b}}{\%}$ & Copolymer & $M_{\mathrm{n}}^{\mathrm{c}}$ & $M_{\mathrm{w}} / M_{\mathrm{n}}^{\mathrm{c}}$ \\
\hline 1 & 180 & 188 & None & & & 0.0 & PBS1 & 32400 & 1.63 \\
\hline 2 & 180 & 186 & 3a & Methyl & 0.54 & 0.3 & $\operatorname{PBSM}(0.3)$ & 68500 & 1.99 \\
\hline 3 & 180 & 185 & $3 \mathbf{a}$ & Methyl & 1.99 & 1.0 & PBSM(1) & 62500 & 2.05 \\
\hline 4 & 180 & 185 & $3 \mathbf{a}$ & Methyl & 3.67 & 2.0 & PBSM(2) & 49200 & 1.60 \\
\hline 5 & 180 & 171 & $3 a$ & Methyl & 9.06 & 5.0 & PBSM(5) & 33800 & 1.32 \\
\hline 6 & 180 & 186 & $3 \mathbf{b}$ & Allyl & 0.84 & 0.5 & PBSA(0.5) & 71300 & 2.17 \\
\hline 7 & 180 & 185 & $3 b$ & Allyl & 1.76 & 1.0 & PBSA(1) & 79000 & 2.15 \\
\hline 8 & 180 & 186 & $3 b$ & Allyl & 3.60 & 2.0 & PBSA(2) & 63500 & 2.11 \\
\hline 9 & 180 & 171 & $3 b$ & Allyl & 9.10 & 5.0 & PBSA(5) & 35900 & 1.78 \\
\hline 10 & 180 & 187 & $3 c$ & Octadecyl & 0.38 & 0.2 & PBSO(0.2) & 63700 & 1.75 \\
\hline 11 & 180 & 187 & $3 c$ & Octadecyl & 0.54 & 0.3 & $\operatorname{PBSO}(0.3)$ & 68900 & 1.65 \\
\hline 12 & 180 & 187 & $3 c$ & Octadecyl & 0.95 & 0.5 & PBSO(0.5) & 43600 & 1.40 \\
\hline 13 & 180 & 186 & $3 c$ & Octadecyl & 1.80 & 1.0 & PBSO(1) & 22900 & 1.53 \\
\hline
\end{tabular}

Table II. Thermal properties of copolymers

\begin{tabular}{clcccc}
\hline Run & Copolymer & $T_{\mathrm{g}}\left({ }^{\circ} \mathrm{C}\right)$ & $T_{\mathrm{m}}\left({ }^{\circ} \mathrm{C}\right)$ & $\Delta H_{\mathrm{m}}\left(\mathrm{mJ} \mathrm{mg}^{-1}\right)$ & $\mathrm{Td} 2$ \\
\hline 1 & PBS1 & -39.9 & 114.1 & 110.1 & 322.2 \\
2 & PBSM(0.3) & -34.8 & 114.9 & 69 & 299.3 \\
3 & PBSM(1) & -38.1 & 115.3 & 80.10 & 309.9 \\
4 & PBSM(2) & -35.2 & 113.7 & 76.10 & 299.8 \\
5 & PBSM(5) & -35.3 & 113 & 65.00 & 309.9 \\
6 & PBSA(0.5) & -36.6 & 114.9 & 72.4 & 303.2 \\
7 & PBSA(1) & -43.2 & 111.9 & 75.40 & 309.9 \\
8 & PBSA(2) & -37.6 & 114.1 & 71.70 & 304.3 \\
9 & PBSA(5) & -39.1 & 111.9 & 76.60 & 317.7 \\
10 & PBSO(0.2) & -35.2 & 114.1 & 100.7 & 300.9 \\
11 & PBSO(0.3) & -41.9 & 114.9 & 82.30 & 313.0 \\
12 & PBSO(0.5) & -39.9 & 114.9 & 85.40 & 311.8 \\
13 & PBSO(1) & -43.5 & 114.9 & 93.50 & 283.5 \\
\hline
\end{tabular}

lowered $M_{\mathrm{n}}$ of the copolymer. The cause was considered the low reactivity of secondary alcohol of $\mathbf{3}$.

Table II shows the thermal properties of the obtained copolymers. Glass transition temperature $\left(T_{\mathrm{g}}\right)$ and melting temperature $\left(T_{\mathrm{m}}\right)$ did not changed much in the experiments. This means that the copolymers have the almost same thermal properties.

Table III shows the tensile tests of obtained copolymers. PBS copolymers including $0.3 \%$ and $0.5 \%$ of monoacylglycerol have larger break strain than PBS homopolymer. ${ }^{8}$ Also in Table III, copolymers PBSM(0.3), PBSM(1), PBSM(2), PBSA(0.5), PBSA(1), PBSA(2), PBSO(0.2), PBSO(0.3), and PBSO(0.5) have larger break strain than homopolymer, PBS1. But PBSM(5), PBSA(5), and PBSO(1) were very brittle and had small break strain. It was considered that the cause of brittleness was the small molecular weight of copolymers.

Figure 1 shows the relationship between added $\mathbf{3}$ and break strain. PBSO(0.3) which is the copolymer including $0.3 \mathrm{~mol} \%$ of $\mathbf{3 c}$ had the largest break strain of 469.9\%. PBSO(0.5) and PBSO(1) including more 3c

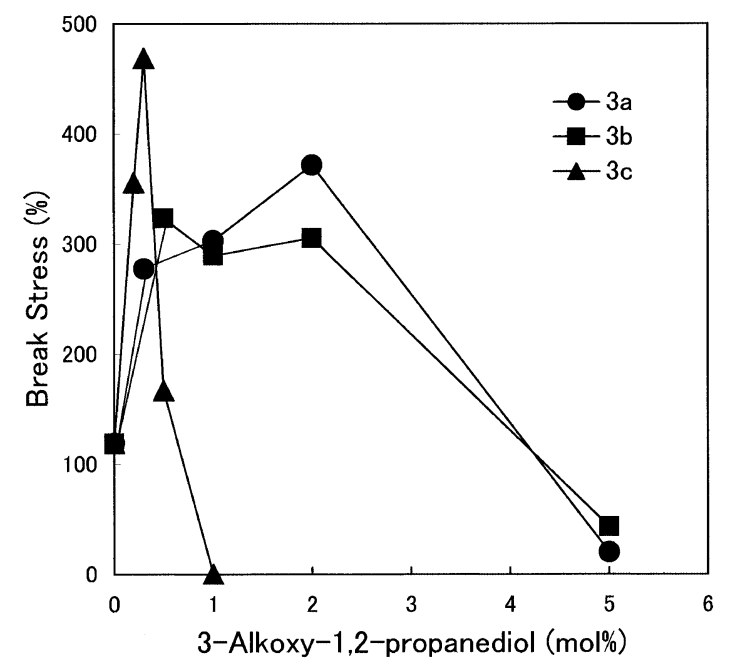

Figure 1. Break strain of copolymers including 3-alkoxy-1,2propanediol.

lowered the break strain. The cause was considered that the low reactivity of secondary alcohol of $\mathbf{3 c}$ decreased the $M_{\mathrm{n}}$. So a method was designed in which diols of $3 \mathbf{c}$ are esterified at first by succinic anhydride and then copolymerization reaction is carried out (Scheme 2). 
Copolymer of PBS with 3-Alkoxy-1,2-propanediol

Table III. Tensile strength of coplymers

\begin{tabular}{|c|c|c|c|c|c|}
\hline Run & Copolymer & $\frac{\text { Elastic }}{\mathrm{MPa}}$ & $\frac{\text { Yield Stress }}{\mathrm{MPa}}$ & $\frac{\text { Break Stress }}{\mathrm{MPa}}$ & $\frac{\text { Break Strain }}{\%}$ \\
\hline 1 & PBS1 & 333 & 32.4 & 29.9 & 119.3 \\
\hline 2 & $\operatorname{PBSM}(0.3)$ & 292 & 26.6 & 29.8 & 277.6 \\
\hline 3 & PBSM(1) & 500 & 22.9 & 59.5 & 303.1 \\
\hline 4 & $\operatorname{PBSM}(2)$ & 317 & 26.7 & 35.3 & 371.6 \\
\hline 5 & PBSM(5) & 319 & 26.4 & 27.30 & 20.0 \\
\hline 6 & $\operatorname{PBSA}(0.5)$ & 274 & 26.3 & 34.3 & 323.5 \\
\hline 7 & PBSA(1) & 472 & 21.9 & 55.8 & 289.4 \\
\hline 8 & PBSA(2) & 309 & 27.3 & 32.7 & 305.3 \\
\hline 9 & PBSA(5) & 329 & 25.7 & 26.10 & 43.1 \\
\hline 10 & $\operatorname{PBSO}(0.2)$ & 308 & 28.0 & 34.9 & 355.8 \\
\hline 11 & PBSO(0.3) & 277 & 24.7 & 40.3 & 469.9 \\
\hline 12 & PBSO(0.5) & 269 & 27.1 & 26.1 & 166.9 \\
\hline 13 & PBSO(1) & brittle & $\mathrm{x}$ & $\mathrm{x}$ & $\mathrm{x}$ \\
\hline
\end{tabular}

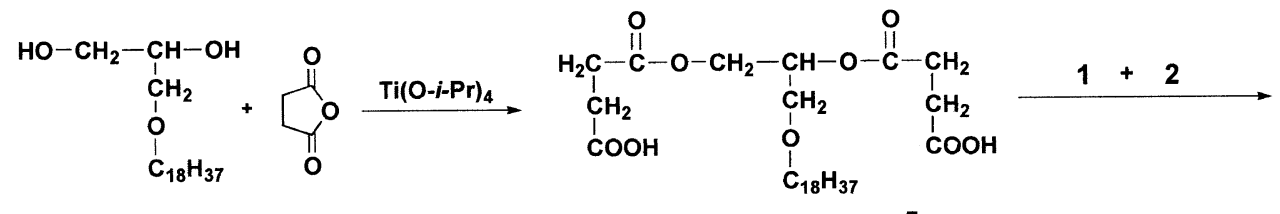

$3 c$

4

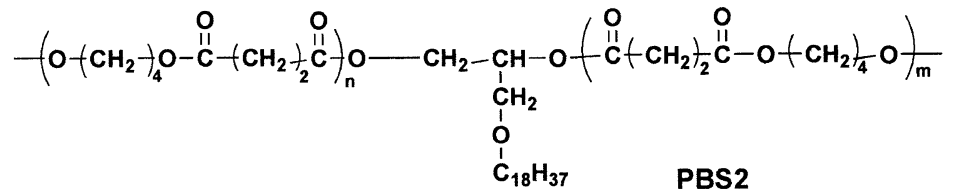

Scheme 2.

Table IV. $M_{\mathrm{n}}$ and $M_{\mathrm{w}} / M_{\mathrm{n}}$ of copolymers including 3-octadecyloxy-1,2-propanediol ${ }^{\mathrm{a}}$

\begin{tabular}{|c|c|c|c|c|c|c|c|c|c|}
\hline \multirow{2}{*}{ Run } & \multirow{2}{*}{$\frac{1}{\mathrm{mmol}}$} & \multirow{2}{*}{$\frac{\mathbf{4}}{\mathrm{mmol}}$} & \multirow{2}{*}{$\frac{\mathbf{2}}{\mathrm{mmol}}$} & \multirow{2}{*}{$\frac{\mathbf{3 c}}{\mathrm{mmol}}$} & \multicolumn{2}{|c|}{$3 c /(1+4)^{b}(\%)$} & \multirow{2}{*}{ Copolymer } & \multirow{2}{*}{$M_{\mathrm{n}}{ }^{\mathrm{c}}$} & \multirow{2}{*}{$M_{\mathrm{w}} / M_{\mathrm{n}}{ }^{\mathrm{c}}$} \\
\hline & & & & & Feed & Copolymer & & & \\
\hline 1 & 130 & 50 & 187 & 0 & 0 & 0 & PBS2(0) & 69400 & 1.90 \\
\hline 2 & 130 & 50 & 189 & 0.54 & 0.3 & obscure & PBS2(0.3) & 97100 & 2.07 \\
\hline 3 & 130 & 50 & 188 & 0.90 & 0.5 & obscure & PBS2(0.5) & 78200 & 1.91 \\
\hline 4 & 130 & 50 & 188 & 1.8 & 1.0 & 1.6 & PBS2(1) & 64300 & 1.86 \\
\hline 5 & 130 & 50 & 188 & 3.6 & 2.0 & 2.6 & PBS2(2) & 98300 & 1.74 \\
\hline 6 & 130 & 50 & 188 & 9.0 & 5.0 & 5.9 & PBS2(5) & 71800 & 1.77 \\
\hline 7 & 130 & 50 & 170 & 18.0 & 10.0 & 11.5 & PBS2(10) & 31200 & 1.70 \\
\hline
\end{tabular}

Table IV shows the $M_{\mathrm{n}}$ and $M_{\mathrm{w}} / M_{\mathrm{n}}$ of the copolymers synthesized by the new method. This method accelerated polymerization and a homopolymer with higher molecular weight than that by former method was obtained. Copolymers with $M_{\mathrm{n}}$ higher than 60000 could be obtained at $0-5 \mathrm{~mol} \%$ of $3 \mathbf{c}$ in copolymerization. Copolymerization with $10 \mathrm{~mol} \%$ of $\mathbf{3 c}$ was very slow and could not give similar $M_{\mathrm{n}}$ to the others. The composition of $\mathbf{3 c}$ in the copolymers was approximately estimated from the methylene proton resonance intensities of $\mathrm{CH}_{2}(\mathrm{~d})$ and $\left(\mathrm{CH}_{2}\right)_{15}(\mathrm{~b})$ as shown in Figure 2. The compositions of 3c in PBS2(0.3) and PBS2(0.5) were obscure because of the few peaks $b$.
Table V. Thermal properties of copolymers

\begin{tabular}{clcccc}
\hline Run & Copolymer & $T_{\mathrm{g}}\left({ }^{\circ} \mathrm{C}\right)$ & $T_{\mathrm{m}}\left({ }^{\circ} \mathrm{C}\right)$ & $\Delta H_{\mathrm{m}}\left(\mathrm{mJ} \mathrm{mg}^{-1}\right)$ & $\mathrm{Td} 2$ \\
\hline 1 & PBS2(0) & -35.9 & 116.1 & 108.1 & 309.3 \\
2 & PBS2(0.3) & -36.6 & 114.9 & 66.5 & 306.9 \\
3 & PBS2(0.5) & -38.0 & 113.7 & 93.4 & 300.7 \\
4 & PBS2(1) & -36.7 & 115.0 & 98.9 & 310.5 \\
5 & PBS2(2) & -36.6 & 113.7 & 88.3 & 310.6 \\
6 & PBS2(5) & -36.4 & 108.8 & 89.4 & 308.1 \\
7 & PBS2(10) & -18.8 & 105.2 & 94.3 & 307.6 \\
\hline
\end{tabular}

The composition of $\mathbf{3 c}$ in copolymer was similar to the feed composition of $\mathbf{3 c}$ at 1 to $10 \mathrm{~mol} \% \mathbf{3 c}$.

Table $\mathrm{V}$ shows the thermal properties of obtained 


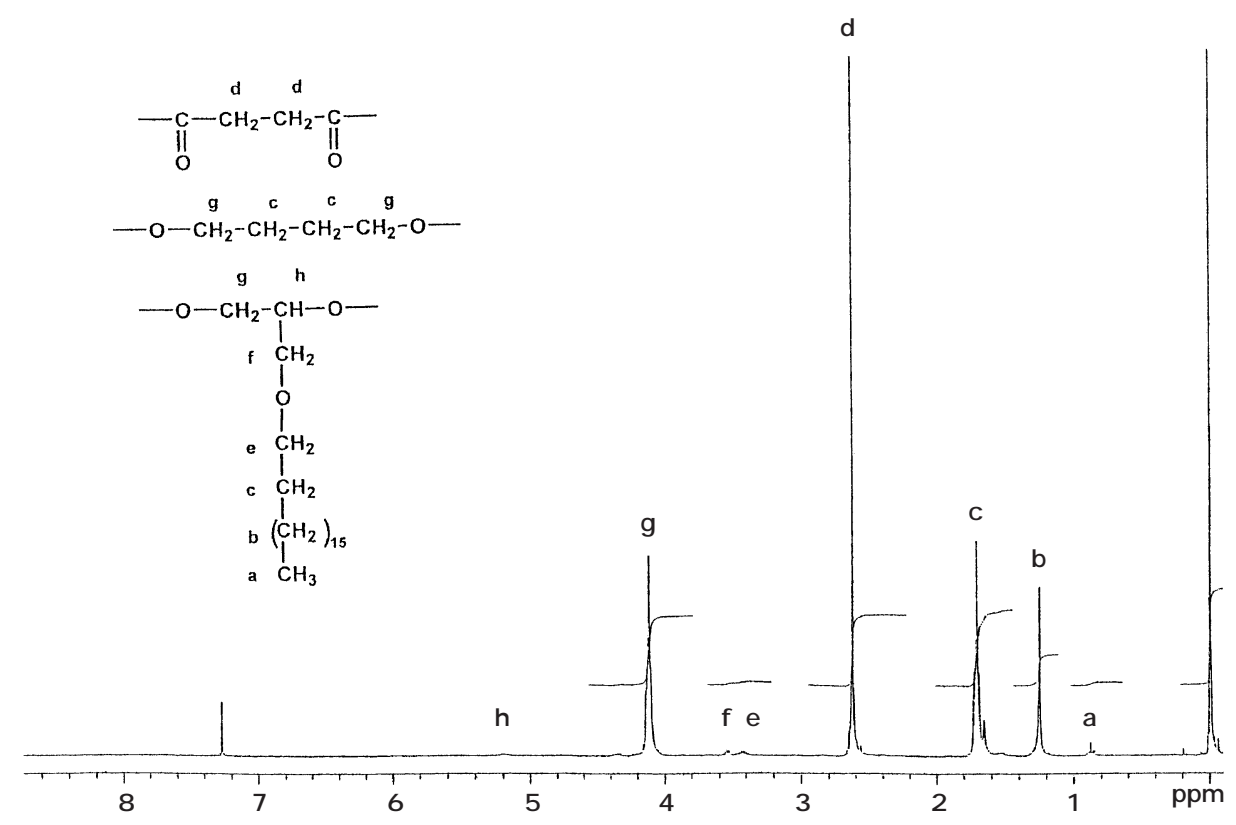

Figure 2. ${ }^{1} \mathrm{H}$ NMR spectrum of PBS2(5).

Table VI. Tensile strength of coplymers

\begin{tabular}{|c|c|c|c|c|c|}
\hline Run & Copolymer & $\frac{\text { Elastic }}{\mathrm{MPa}}$ & $\frac{\text { Yield Stress }}{\mathrm{MPa}}$ & $\frac{\text { Break Stress }}{\mathrm{MPa}}$ & $\frac{\text { Break Strain }}{\%}$ \\
\hline 1 & PBS2(0) & 239 & 27.2 & 35.5 & 370.2 \\
\hline 2 & PBS2(0.3) & 216 & 23.1 & 56.3 & 720.7 \\
\hline 3 & PBS2(0.5) & 225 & 24.8 & 51.5 & 709.5 \\
\hline 4 & PBS2(1) & 260 & 22.3 & 50.0 & 730.7 \\
\hline 5 & PBS2(2) & 180 & 20.5 & 50.9 & 777.0 \\
\hline 6 & PBS2(5) & 147 & 17.2 & 40.5 & 833.4 \\
\hline 7 & PBS2(10) & 131 & 13.8 & 13.7 & 16.4 \\
\hline
\end{tabular}

copolymers. These properties were not so changed at 0 to $10 \mathrm{~mol} \%$ of $\mathbf{3 c}$.

Table VI shows the tensile tests of copolymers. Homopolymer PBS2(0) shows greater break strain than PBS1 because of high $M_{\mathrm{n}}$ of 69400 . The elastic modulus and yield stress decreased, and break strain increased with $\mathbf{3 c}$ in the copolymers. A copolymer thus becomes more flexible with $\mathbf{3 c}$. When $5 \mathrm{~mol} \%$ of $\mathbf{3 c}$ was included in a copolymer the break stress of the copolymer was $833 \%$.

Biodegradation kinetics are important in biodegradable plastics. Figure 3 shows the biodegradation experimental results of PBS2(0), PBS2(1), and PBS2(5) film samples in commercial compost soil under $30^{\circ} \mathrm{C}$ and $95 \% \mathrm{RH}$. Biodegradability was thus expressed as weight loss as a function of buried time for $25 \times 25 \mathrm{~mm}$ film samples. Although the biodegradability of PBS2(0) and PBS2(1) was almost the same, weight loss of PBS2(5) was less than PBS2(0) and PBS2(1). Although many copolymers are more biodegradable than the homopolymer for the low crystallinity, ${ }^{7,9}$ copolymer PBS2(5) was less biodegradable than the homopolymer PBS2(0), possibly because of the hy-

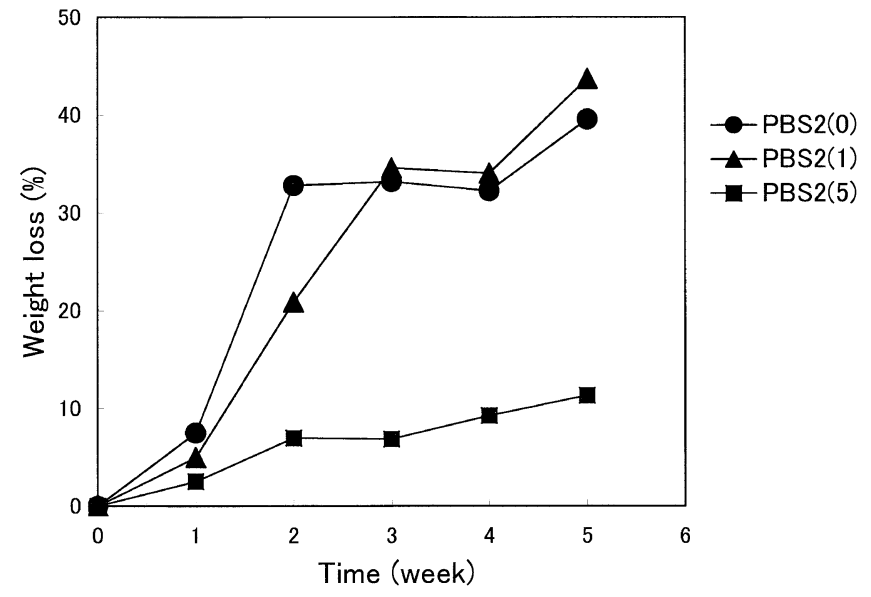

Figure 3. Buried time dependence of biodegradation.

drophobic alkyl long chain of 3c. Biodegradability control may be possible according to type and composition of 3 .

\section{CONCLUSION}

Poly(butylene succinate) copolymers including small amount of $\mathbf{3}$ had larger break strain than homopolymer. 
Molecular weight decreased with increasing $\mathbf{3}$, because the secondary alcohol of $\mathbf{3}$ was less reactive than the other primary alcohols, and could not be esterified nor copolymerization made progress. Only $1 \mathrm{~mol} \% \mathbf{3 c}$ having an alkyl long chain decreased $M_{\mathrm{n}}$ of copolymer at 23000 . The copolymer including $0.3 \% \mathbf{3 c}$ had the largest break strain. So a new synthetic method to accelerate copolymerization was designed so that diols of 3c are first esterified by succinic anhydride and then copolymerization with 1,4-butanediol. $M_{\mathrm{n}}$ of copolymers at 0 to $5 \mathrm{~mol} \%$ of $3 \mathbf{c}$ were higher than 60000 using the new method. The elastic modulus and yield stress of copolymers decreased, and break strain increased with $3 \mathbf{c}$ in copolymers. The copolymer thus becomes more flexible with increasing 3c. At $5 \mathrm{~mol} \% \mathbf{3 c}$ in the copolymer, break stress reached $833 \%$.

Biodegradation tests of copolymers were carried out in commercial compost soil under $30^{\circ} \mathrm{C}$ and $95 \% \mathrm{RH}$. Although the biodegradability of PBS2(0) and PBS2(1) was almost the same, the weight loss of PBS2(5) was less than PBS2(0) and PBS2(1). The delay of biodegra- dation by copolymerization with $\mathbf{3 c}$ shows the possibility of biodegradability control by type and composition of 3 .

\section{REFERENCES}

1. S. Takenouchi, A. Takasu, Y. Inai, and T. Hirabayashi, Polym. $J .$, 33, 746 (2001).

2. T. Hayashi, H. Kanai, and T. Hayashi, Polym. J., 33, 38 (2001).

3. J. Li, Y. He, and Y. Inoue, Polym. J., 33, 336 (2001).

4. H. Pranamuda, R. Chollakup, and Y. Tokiwa, Appl. Env. Microbiology, 65, 4220 (1999).

5. Y. He, T. Masuda, A. Cao, N. Yoshie, Y. Doi, and Y. Inoue, Polym. J., 31, 184 (1999).

6. H. Pranamuda, Y. Tokiwa, and H. Tanaka, Appl. Env. Microbiology, 61, 1828 (1995).

7. A. Cao, T. Okamura, C. Ishiguro, K. Nakayama, Y. Inoue, and T. Masuda, Polymer, 43, 671 (2002).

8. Y. Taguchi, A. Oishi, K. Fujita, Y. Ikeda, K. Watanabe, and T. Masuda, J. Oleo Sci., 49, 825 (2000).

9. H. Shirahama, A. kanetani, and H. Yasuda, Polym. J., 32, 280 (2000). 